\title{
Objects or Others? Epistemic Agency and the Primary Harm of Testimonial Injustice
}

\author{
Aidan McGlynn ${ }^{1}$ \\ Accepted: 9 March 2020 / Published online: 14 March 2020 \\ (C) The Author(s) 2020
}

\begin{abstract}
This paper re-examines the debate between those who, with Miranda Fricker, diagnose the primary, non-contingent harm of testimonial injustice as a kind of epistemic objectification and those who contend it is better thought of as a kind of epistemic othering. Defenders of the othering account of the primary harm have often argued for it by presenting cases of testimonial injustice in which the testifier's epistemic agency is affirmed rather than denied, even while their credibility is unjustly impugned. In previous work, I have instead argued that such cases suggest that we need to enrich our conception of epistemic objectification in ways encouraged by Martha Nussbaum's cluster analysis of objectification. Here I continue to make the case for this approach, and I consider the othering account in more detail. I focus in particular on Gaile Pohlhaus Jr.'s arguments for a version of the othering account in terms of the notion of derivatization, which turns on the idea that only such an account can enable us to properly understand the harms of testimonial injustice, in particular the ways in which it interferes with a subject's epistemic agency and autonomy, and I'll argue that such arguments should not sway us. Finally, I'll further support my contention that it is illuminating and helpful to think of the primary harm of testimonial injustice in terms of epistemic objectification, though I will concede that the notion of epistemic othering may offer further helpful resources for understanding how subjects can be harmed by testimonial injustice.
\end{abstract}

Keywords Testimonial injustice · Epistemic agency · Objectification · Othering · Gaslighting

\section{Introduction: The Primary Harm of Testimonial Injustice}

In Anthony Minghella's screenplay of Patricia Highsmith's The Talented Mr Ripley, Marge Sherwood has well-founded suspicions that Tom Ripley is involved in the disappearance of her fiancé, Dickie Greenleaf. She voices these suspicions to Dickie's father, Herbert Greenleaf,

Aidan McGlynn

amcglynn@staffmail.ed.ac.uk

1 Department of Philosophy, University of Edinburgh, Edinburgh, Scotland 
only to be dismissed: 'Marge, there's female intuition, and then there are facts' (Minghella 2000: 130). In Harper Lee's To Kill a Mockingbird (1960), a disabled black man, Tom Robinson, testifies truly that he is innocent of the crime he has been accused of, raping a young white woman, Mayella Ewell. Robinson's lawyer, Atticus Finch, conclusively demonstrates Robinson's innocence to the jury, but despite this, Robinson finds it impossible to get the all-white jury to accept his testimony, and they find him guilty, with lethal consequences.

These well-known fictional examples are Miranda Fricker's principle illustrations of testimonial injustice, which involves a speaker being accorded less credibility by their audience that they are due, as a result of prejudices held by that audience against people who share the speaker's social identity (their gender or race, for example). The two examples differ in the way that these prejudices target the speaker's credibility. Greenleaf's prejudices target Sherwood's credibility by painting her as epistemically incompetent, while the jury's prejudices against Tom Robinson target his credibility by painting him as insincere. Despite these differences between Fricker's two main examples of testimonial injustice, she thinks she can give a unified account of what she calls the primary harm of testimonial injustice (2007: 45): a harm that is not contingent, but rather inherent and intrinsic to testimonial injustice. This primary harm also reveals in what sense testimonial injustice is a form of epistemic injustice: injustice that harms one specifically in one's capacity as a knower (or better, in one's capacity as an epistemic agent - see Gerken 2019: 2). In particular, an account of the primary harm of testimonial injustice will reveal the way in which it harms one in one's capacity as a giver of knowledge (Fricker 2007: 45). The primary harm of testimonial injustice is the topic of the present paper.

Fricker identifies the primary epistemic and ethical harm of testimonial injustice as a kind of epistemic objectification, where this is understood along the lines of Martha Nussbaum's influential analysis of objectification (Nussbaum 1995). In particular, Fricker proposes that the primary harm of testimonial injustice is that an epistemic agent is treated as epistemically inert: as lacking epistemic agency. However, a number of critics have drawn attention to cases of testimonial injustice which don't seem to involve treating a testifier as inert, and many of these critics have appealed to these cases to motivate an alternative to Fricker's account of the primary harm. On this alternative account, the primary harm of testimonial injustice is not that one treats a subject as an object, but rather that one treats them as an epistemic other. Epistemic others are not treated as lacking agency altogether, but their agency is only partially recognised. In earlier work [McGlynn forthcoming], I have argued that Fricker's critics are quite correct to hold that there are examples of testimonial injustice that don't involve treating a testifier as inert, but I have tried to undermine the support such examples provide for an account of the primary harm in terms of epistemic othering by showing that the objectification account, suitably understood, can accommodate the problem examples.

This is where my earlier argument left things, and so it left open the question of which, if either, of these two accounts of the examples is to be preferred. The task of this paper is respond in more detail to the case that has been made against the objectification account, with particular focus on the series of challenges that Gaile Pohlhaus Jr. has offered to it, and to begin to make a positive case for the claim that the resources that it offers are ones we need. To achieve this latter goal, the final section examines some cases of testimonial injustice that accounts of the primary harm in terms of epistemic othering struggle to accommodate, and which demonstrate the advantages of the flexibility afforded by the version of the objectification account I advocate. 


\section{Epistemic Inertness}

I'll start by introducing Fricker's account of the primary harm in a little more detail, and presenting the cases that it struggles to accommodate. I'll then outline the two accounts that attempt to improve on Fricker's; one which retains her core idea that the primary harm is a kind of objectification, and the rival account in terms of othering.

Why think that testimonial injustice involves objectification? Fricker starts from a distinction she takes from Edward Craig's work on the social function of the concept of knowledge (1990), between informants and mere sources of information:

Broadly speaking, informants are epistemic agents who convey information, whereas sources of information are states of affairs from which the inquirer may be in a position to glean information. Thus, while objects can only be sources of information, people can be either informants (as when someone tells one something one wants to know) or sources of information (as when the fact that one's guest arrives bedraggled and shaking her umbrella may allow one to infer it has been raining). (2007: 132)

Fricker's proposal, then, is that testimonial injustice involves treating someone as a mere source of information rather than as an informant due to one's prejudices, and that this is a form of objectification. It's objectifying because it involves casting a testifier in 'the role of passive state of affairs from which knowledge might be gleaned' or 'passive bystander', relegating them 'to the same status as a felled tree whose age one might glean from the number of rings' (132-3). In other words, it involves treating them as epistemically inert - as lacking epistemic agency. This is a form of epistemic objectification since inertness is one of the seven ways of treating someone as an object, according to Nussbaum (1995: 257):

1. Instrumentality: the objectifier treats the object as a tool of his or her purposes.

2. Denial of Autonomy: the objectifier treats the object as lacking in autonomy and selfdetermination.

3. Inertness: the objectifier treats the object as lacking in agency, and perhaps also in activity.

4. Fungibility: the objectifier treats the object as interchangeable with other objects of the same type, or with objects of other types.

5. Violability: the objectifier treats the object as lacking in boundary-integrity, as something it is permissible to break up, smash, break into.

6. Ownership: the objectifier treats the object as something that is owned by another, which can be bought or sold, and so on.

7. Denial of Subjectivity: the objectifier treats the object as something whose experiences and feelings (if any) need not be taken into account.

As we've seen, Fricker's application of Nussbaum's analysis to the epistemic sphere appeals almost entirely to the third item on Nussbaum's list, inertness; in cases of testimonial injustice, one prejudicially treats a testifier as mere source of information, and so as lacking epistemic agency. Fricker's idea isn't that treating someone as a mere source of information is always morally and epistemically problematic, as is shown by the example of the bedraggled guest in the quote above. What's going to matter is the broader context and relationships involved; as Nussbaum says, 'In the matter of objectification, context is everything' (1995: 271). Nussbaum holds that objectification can be a neutral and even a positive part of a relationship, 
as when someone treats their partner's stomach as a pillow, knowing that they don't mind and in the context of a relationship in which they are frequently treated as more than a pillow. Likewise, treating someone as a mere source of information may be harmless so long as one isn't disposed to only treat them this way.

The problem with Fricker's account is that there seem to be cases of testimonial injustice that don't involve an audience treating the speaker as epistemically inert in anything like this sense. The literature has identified three main kinds of cases. José Medina has suggested that one can subject someone to a testimonial injustice even while treating them as an informant, and not merely as a source of information. This is because treating someone as an informant is compatible with failing to recognize them as an inquirer in their own right - failing to recognize them as having an epistemic agenda of their own, from which one potentially stands to gain. Medina thinks that this involves at least a partial recognition of a person's epistemic agency. However, their agency is treated as 'limited and subordinated to that of the inquirer - it is at the service of the inquirer's questions, assessments, and interpretations' (2012: 204).

Emmalon Davis discusses cases in which someone is given a credibility excess, rather than the kind of deficit characteristic of Fricker's cases. In Fricker's book, she argued that credibility excesses don't matter when characterizing the primary harm of testimonial injustice, since rather than harming the speaker, such excesses will typically be to their unfair advantage, and '[do] not undermine, insult, or otherwise withhold proper respect for the speaker' (2007: 20). In response, a number of philosophers have argued that Fricker pays too little attention to the ways that credibility deficits and credibility excesses are intertwined (e.g. Medina 2013; Yap 2017; Manne 2018). The idea is that credibility excesses do in fact harm marginalized testifiers, since assessments of credibility are relative. That means that overinflating one group's credibility comes at the expensive of others, who are liable to receive a relative credibility deficit, as when people believe powerful men over their accusers (Yap 2017 and Manne 2018: chapter 6), or when the jury in Tom Robinson's trial inflate the credibility of his white accusers, leading to Robinson's wrongful conviction (Medina 2013). Such criticisms of Fricker are fair, but as Davis notes (Davis 2016: 497 n2), they don't challenge the core point Fricker makes in the passage just quoted. Davis herself goes further, contending that there are cases in which a speaker is directly and immediately harmed by being given a credibility excess (rather than by someone else being given one). For example, Davis introduces cases in which someone is given a credibility excess due to so-called 'positive stereotypes', as when an Asian-American student is treated as authoritative when it comes to mathematics. Being treated this way may lead to all kinds of downstream harms; for example, the expectation that one get things right and the assumption that one is representing one's social group may cause stress and set a speaker up for unwarranted embarrassment (2016: 492). But Davis contends that such examples also involve an immediate epistemic and ethical harm to the speaker in their capacity as a giver of knowledge, as in Fricker's cases of credibility deficit. Such cases are therefore relevant when we consider the nature of the primary harm of testimonial injustice, and Fricker's account in terms of imputed epistemic inertness doesn't seem apt at all:

the targets of [credibility excesses] are not regarded simply as passive states of affairs or inert objects from which information might be gleaned nor are they excluded from epistemic participation. (2016: 489) 
The third kind of example that seems problematic for Fricker's account involves speakers whose credibility is unjustly downgraded because they are seen as lying about matters they are recognized to know about. Matthew Congdon offers an example of this sort, based on a disturbing real-life case of a Muslim man's testimony being (wrongly) dismissed as lies by his interrogators at Guantanamo Bay - as Congdon points out, this whole interaction seems to grant epistemic agency to the man (2017: 247). Arguably another example of this kind is Fricker's own example of Tom Robinson in To Kill a Mockingbird [McGlynn forthcoming]. The jury recognizes that Robinson knows what happened between himself and Mayella Ewell that day, but their prejudices prevent them from recognizing his truthful testimony on this subject for what it is.

While we could argue about the strength of each of these three kinds of examples considered in isolation, together they strongly suggest that the primary harm should not be identified as being treated as epistemically inert — as devoid of epistemic agency. My concern here is with what further conclusions we should draw from these examples. As mentioned in the introduction, most of the philosophers who have drawn attention to these kinds of cases of testimonial injustice have proposed moving away from an account of the primary harm in terms of epistemic objectification, and towards an account in terms of epistemic othering (Pohlhaus 2014; Davis 2016; Congdon 2017; Cusick 2019), and the idea that testimonial injustice involves epistemic othering has also been defended on other grounds by a number of philosophers (e.g. McConkey 2004; Giladi 2017, and Medina 2018).

In contrast, I don't think the problem cases motivate a move away from an account of the primary harm in terms of epistemic objectification, though they do suggest the need for some revisions to Fricker's version of the objectification account [McGlynn forthcoming]. What the cases show, in my view, is that we need to remember that treating someone as inert is just one of seven ways that one can treat someone as an object, according to Nussbaum's 'cluster' analysis, and we should be open to the idea that one can objectify someone while recognizing their agency and autonomy. This is a general point which, if it can be demonstrated, should help to defend the concept of objectification from some recent challenges (for example, those in Cahill 2011, Mikkola 2016, and Manne 2018). In the specifically epistemological context, the idea is that the examples which are problematic for Fricker's account of epistemic objectification involve ways of objectifying a person which need not implicate their epistemic agency or autonomy. For example, as Davis herself notes (2016: 488), her examples seem to involve speakers being treated as epistemically fungible; the speakers are not credited as having anything unique to contribute, and they are treated as if more or less any other member of their social group would be just as credible on the subject at hand. We can also see an epistemic analogue of what Nussbaum calls instrumentality - the first item on her list above - in this and the other problem examples. I've argued this point elsewhere [McGlynn forthcoming], and I won't repeat that discussion here.

There's an alternative move that the defender of the objectification account could make here, suggested by Jeremy Wanderer (2012) in another context. Wanderer's own project is accounting for the significance of a distinction between ignoring a person's testimony and rejecting it. Part of his account involves appealing to notions of interpersonal recognition, which brings him close to recent discussions of testimonial injustice inspired by Honneth, discussed in the next section. However, Wanderer also endorses Fricker's objectification account of the harm of testimonial injustice, but argues that the distinction between ignoring and rejecting testimony shows that Fricker's account needs refinement (2012: 164-5). 
Wanderer here appeals to Rae Langton's (2005) distinction between two different ways one might 'treat' a person as object-like in some respect. Langton focuses on autonomy-denial, but we can instead draw her distinction in terms of inertness; one can treat someone as inert by treating them as lacking the capacity for agency, or by recognizing but violating their agency.

While this isn't a proposal Wanderer himself makes, we might invoke Langton's distinction to defend Fricker's account of the primary harm of testimonial injustice. Perhaps the speakers in the problem cases described above do have their epistemic agency denied, but in the second way distinguished by Langton rather than the first; unlike a felled tree, these speakers do have their epistemic agency affirmed by their audiences, but it is affirmed only so that it can be violated. This is a possible move one could make, though I have two reservations. First, it's not clear why we should think of recognizing someone's agency or autonomy only to violate it as a way of treating them as object-like; this is a delicate matter, which demands a much longer discussion than I can give it here. Second, it's not clear that this kind of elaboration of Fricker's account helps with all of the problem cases introduced above. Consider Davis's cases of credibility excesses given to those who are forced into playing the role of representatives or spokespersons for a particular social group. It's not immediately obvious what the intrinsic harm of such cases of testimonial injustice is, but I doubt it's helpful to think in terms of the violation of the speakers' epistemic agency. On the face of it that seems like a peculiar description of what's going on when an Asian-American student's answers to questions on a mathematics quiz are given more weight than they ought to be, for example. I'll offer my own account of the harm perpetrated in such examples below in section 4, and it will appeal to my own preferred way of enriching Fricker's account of the primary harm, which appeals to the range of different ways that Nussbaum identifies in which we can treat a person as a thing, rather than to Langton's distinction.

This is where I'll leave the discussion of this first attempt to motivate an othering account of the primary harm over the objectification account, since I want to turn to issues which haven't received as much attention in the literature already. In the next section of this paper, I'll consider further arguments for an othering account over an objectification account, focusing on Pohlhaus's discussion, and I'll argue that these arguments should be resisted. In the final section, I'll offer some reasons for thinking that my preferred version of the objectification account offers a rich and helpful account of the primary harm of testimonial injustice, boasting advantages which may not be matched by an account in terms of othering.

\section{Overcoming Epistemic Objectification?}

My task is made more difficult by the fact that there are really two versions of the othering account in the recent literature (both with roots in the work of Hegel). One of these looks to the work of Axel Honneth (1995) for inspiration (e.g. Congdon 2017 and Giladi 2017; see Wanderer 2012 for a related proposal). The other offers an epistemological spin on Ann Cahill's (2011) general insistence that we need to 'overcome' objectification, and that the work we want that notion to do is better approached with a particular notion of othering that she calls derivatization (e.g. Pohlhaus 2014; Davis 2016; Cusick 2019). These two versions of the othering account have appeared without any apparent interaction or acknowledgment of each other, and there are important differences between them.

Those in the first camp have tended to offer relatively detailed discussions of how Honneth's rich account of othering as a kind of failure to recognize another person 
illuminates the harms involved in testimonial injustice. Paul Giladi (2017) and Matthew Congdon (2017) both argue that testimonial injustice involves such failures of recognition. I won't have much to say about this kind of version of the othering account, primarily because I'm not sure how much I disagree. I'm inclined to agree with Fricker's recent acknowledgement of the resources offered by Honneth's recognition theory for understanding the harms of testimonial injustice, and epistemic injustice more generally (Fricker 2018).

My focus will instead be on the second version of the othering account, and in particular, I'll examine Gaile Pohlhaus Jr.'s account of the primary harm as epistemic derivatization. As mentioned, Pohlhaus (and following her, Davis and Cusick) look to Ann Cahill's Overcoming Objectification (2011) for an understanding of othering. As the title of her book suggests, Cahill thinks that the notion of objectification isn't fit for feminist purposes, and she offers instead the notion of derivatization:

To derivatize is to portray, render, understand, or approach a being solely or primarily as the reflection, projection, or expression of another being's identity, desires, fears, etc. (2011: 32)

The notion of derivatization and Cahill's arguments for preferring it to objectification need a much more extensive discussion than I can give them here, and my focus is rather Pohlhaus's development of Cahill's ideas into an account of the primary harm of testimonial injustice. Pohlhaus starts by offering a characterisation of what derivatization looks like in the epistemic domain:

Epistemically speaking, we might say that the derivatizer treats the derivatized as though she has nothing unique to contribute to the intersubjective relations that maintain epistemic practices, even while he does recognize her as capable of some sorts of epistemic labor. In other words, she is treated as if her own lived experience from which she draws in order to add to the communal knowledge pool is simply a mirror (or perhaps shadow) of his own, but certainly not capable of contributing to our understanding of the world beyond (and in ways that might change the shape of) the scope of the derivatizer's experienced world. (2014: 106; see also 107)

This offers a notion of epistemic othering since derivatization is a development of Beauvoir's exploration of women as 'the Other' in The Second Sex (Pohlhaus 2014: 104-5). But why favour such an account over Fricker's objectification account? Pohlhaus's main consideration is a version of the objection to Fricker considered above, which turns on the observation that there are cases of testimonial injustice which don't plausibly involve the speaker being treated as epistemically inert. For reasons I've already explained, I don't think this kind of objection forces us to abandon a suitably rich version of the objectification account (and moreover there are particular problems with Pohlhaus's version of the objection, which I've discussed elsewhere [McGlynn forthcoming: section 2]). However, Pohlhaus goes on to offer four other arguments in favour of thinking of the harm of testimonial injustice in terms of the subject/ other relation rather than the subject/object relation, and so let's turn to those.

First, Pohlhaus suggests that, unlike Fricker's appeal to epistemic objectification, appealing to derivatization allows us to explain why an audience typically doesn't regard a speaker they are prejudiced against as lacking credibility across the board, but only with respect to certain topics. As Fricker herself notes, Tom Robinson would be frequently believed on various topics 
by 'even the most thoroughly racist white citizens of Maycomb County' (2007: 131); while they might think him incapable of telling the truth about his interactions with Mayella Ewell, they would likely take him to be trustworthy concerning banal everyday matters. Likewise, Herbert Greenleaf readily accepts much of Marge Sherwood's testimony concerning the circumstances surrounding the disappearance of her son, even while dismissing her wellfounded suspicions about Ripley. However, Pohlhaus thinks that Fricker fails to explain how this is so. On Fricker's account, testimonial injustice is often a matter of seeing someone as less credible than one ought to, given one's prejudices, and this isn't something which is under one's voluntary control. Nor is it clear what other 'mechanism' might account for the shifts in when we believe someone's testimony, and so treat them as an epistemic subject, and when we don't, thereby treating them as a mere object. In contrast, Pohlhaus argues that a natural explanation is available in terms of epistemic derivatization:

In both cases [Tom Robinson and Marge Sherwood], hearers do not fail to believe mere pieces of information that would simply add to what it is they know, but rather they fail to believe precisely the kind of information that would significantly move the hearers' epistemic attention beyond the parts of the world in which those hearers have a social investment. In other words, hearers perceive the speaker as credible only when the speaker's testimony does not trouble the scope of the hearers' subjectivity. The effect is to rule out the possibility that there might be aspects of the world that go beyond the experiences and interests of those with social power. (2014: 108)

It's not clear to me that the account Pohlhaus offers here is needed. I agree with Fricker and Pohlhaus that whether a speaker is liable to be subject to a testimonial injustice depends not just on their audience, but also on the topic at hand and the content of the particular things they say. However, this seems to be best explained in terms of the particular prejudices operating in a given case of testimonial injustice. Let me illustrate what I mean. In the case of Tom Robinson, the prejudices against him as a black man include that he is a rapist who cannot be trusted around white women (Fricker 2007: 25). The further stereotype that black men lie implicitly relates to these other stereotypes. When Atticus Finch calls for the jury to shake off the 'evil assumption' that all black men lie (Lee 1960: 225), he's not assuming that they take all black men to lie all the time about everything. Likewise, the prejudices working against Sherwood are that as a young, naïve, unmarried woman, she isn't well placed to know what kinds of things young men get up to when left to themselves. The content of these prejudices again seems like it partly explains the boundaries of what kinds of testimony Greenleaf will readily accept from Marge and what kinds he dismisses. As Fricker stresses, there are other dynamics in play too. For example, in Robinson's case, these relate to the racist social hierarchy that's in place. Fricker notes that in order to be found credible, Robinson needs to restrict himself to topics where there's 'no challenge to a white person's word, no perceived implication of non-inferiority of intellect' (2007: 131) — of course, in the courtroom he finds himself in circumstances which make this impossible. Kate Manne has noted that this illustrates a common feature of cases of testimonial injustice, namely that they involve 'a historically subordinate group member trying to testify against a dominant social actor, in the relevant social context' (2018: 193-4). Manne suggests that testimonial injustice often serves the function of upholding and protecting social hierarchies of this sort, and so testimony that doesn't challenge any hierarchy may be accepted even when it comes from a member of a group that one harbours prejudices against. 
These are the kinds of factors I think we should appeal to in explaining why testimonial injustice tends to relate only to some of a person's testimony, and in explaining the location of the boundary between the testimony a given audience will accept and that which they'll reject. It's not clear that there's any residual explanatory work left for the kind of proposal Pohlhaus wants, nor does she offer any examples that seem like they're best explained with appeal to the notion of derivatization.

Pohlhaus's second point is very briefly made (2014: 108):

Second, [the subject/other model] highlights simultaneously the agential and structural aspects of testimonial injustice, something that Fricker has been criticized for not recognizing (Alcoff 2010; Langton 2010; Maitra 2010)

However, it's not true that Fricker doesn't recognise structural aspects of testimonial injustice. Her discussion identifies testimonial injustice as a particular type of social power, namely identity power, where this is 'an operation of power that depends in some significant degree upon [...] shared imaginative conceptions of social identity' (Fricker 2007: 14). Even when power is exercised by an individual, there will be structural factors at work, as in Fricker's example of a traffic warden's power over drivers (2007: 9-10); a warden exercises power over motorists, but they can only do so in virtue of the authority of certain institutions. Moreover, Fricker acknowledges purely structural exercises of power (2007: 10), and these have a role to play in her account of epistemic injustice. This is not to say that there's no room to criticise Fricker for failing to sufficiently pay attention to structural factors, as the philosophers cited by Pohlhaus do. For example, we might worry that Fricker's main positive proposal to combat epistemic injustice, via the cultivation of certain epistemic virtues, is too individualistic and not structural enough (e.g. Alcoff 2010; Langton 2010; Anderson 2012). I'm sympathetic to such worries, but they don't show that Fricker fails to recognise structural aspects of testimonial injustice, nor do they seem to turn much on Fricker's account of the primary harm of testimonial injustice.

Pohlhaus's third argument for her account of the primary harm in terms of derivatization looks at the ways testimonial injustice impedes a person's epistemic agency and autonomy, where Pohlhaus characterises these as 'one's ability to pursue epistemic projects' and 'one's ability to pursue epistemic projects that stem specifically from one's distinct lived experience' respectively (2014: 110). Pohlhaus's worry seems to be that an account of the primary harm in terms of the contrast between subject and object will inevitably lead us to look at testimonial injustice with a focus on individual agents. As a result we'll ignore the role of 'intersubjective epistemic support' in epistemic agency and autonomy, and so fail to recognise the ways in which testimonial injustice interferes with epistemic agency and autonomy by disrupting intersubjectivity. Pohlhaus is surely right to draw attention to the ways in which testimonial injustice can lead to obstacles to one's ability to pursue epistemic projects that require cooperation from those we're trying to share our knowledge with. In Pohlhaus's example (2014: 110-1), Marge Sherwood is unable to pursue various lines of inquiry concerning her fiancé's disappearance due to Herbert Greenleaf dismissing her well-founded suspicions concerning Ripley, rather than finding ways to help her discover more. What's left unclear is Pohlhaus's justification for her claim that adopting an account of the primary harm of testimonial injustice in terms of epistemic objectification means that we will find ourselves stuck at 'the agential 
level', unable to appreciate the intersubjective and 'structural' features that bear on our abilities to pursue our epistemic projects. That seems like the key point here, but it's not apparent why Pohlhaus thinks we should accept it.

Pohlhaus's fourth and final point is that an account of the primary harm in terms of objectification, in contrast to one in terms of derivatization, misses potential sites of epistemic resistance:

Since the subject/object model emphasizes passivity on the side of the victim and does not distinguish which kind of information is likely to trigger a perception of less credibility, the subject/object lens offers no insight into possibilities for epistemic resistance to testimonial injustice. [...] Stressing passivity on the side of the speaker in relation to the perpetrator, the subject/object frame obscures the fact that nondominantly situated subjects can actively withhold information as well as present information selectively. Moreover, because the subject/object model does not distinguish the kind of information that is likely to be believed from the kind of information that is not, it offers no insight into the ways in which epistemic subjects who are not dominantly situated can and often do aptly negotiate instances of testimonial injustice. The subject/ other model, however, does offer this kind of insight, since it highlights the ways in which epistemic agency may still be operative within specifically delineated regions of the experienced world, even while it may be stymied in others. (2014: 111-2, footnotes omitted)

There are at least three problems with this argument. First, the unfavourable contrast to Pohlhaus's preferred model rests on her earlier contention that we need to appeal to her model in order to 'distinguish which kind of information is likely to trigger a perception of less credibility', and I've already argued that this is not so. Second, and unsurprisingly, I want to resist the idea that an account of the primary harm in terms of epistemic objectification needs to emphasise 'passivity on the side of the victim'. While I agree that this is a fair charge against the version of the account offered by Fricker, I've resisted the idea that this kind of emphasis on passivity is essential to the objectification account. But even setting these points aside, I find Pohlhaus's objection puzzling. On the version of the 'subject/object model' Pohlhaus is criticising, perpetrators of testimonial injustice treat speakers as epistemically passive; but that doesn't mean that these speakers really are epistemically passive, or that we (in our role as theorists) should think of them as such. We can surely see lots of scope for the exercise of epistemic agency, including the kinds of epistemic resistance highlighted by Pohlhaus, even when a speaker's audience may be unable to. Pohlhaus misses this when she writes in the passage quoted above "[s]tressing passivity on the side of the speaker in relation to the perpetrator, the subject/object frame obscures the fact that nondominantly situated subjects can actively withhold information as well as present information selectively'. This fact is obscured to those who misperceive nondominantly situated subjects as epistemically passive, but Pohlhaus's wording makes it seem like it's obscured to us, as theorists, as a result of adopting the wrong model. It's not. Indeed, from our perspective, we can see that being misperceived as lacking epistemic agency opens up space for epistemic resistance. An illustrative example of what I have in mind here is offered by Alison Wylie, in her discussion of Barbara Neely's novel Blanche on the Lam, and the ways in which the main character, Blanche White, is able to glean information as a black housekeeper for a wealthy white family: 
Because Blanche is presumed stupid, and anyway of no account, she is largely invisible to the family she works for. Time and time again she gleans information that is critically important to her survival (literally and figuratively) from conversations conducted in her presence as if she were a piece of furniture, from messes she cleans up, garbage she disposes of, errands she is sent on: 'As far as the Graces of the world were concerned, hired hands didn't think, weren't curious, or observant, or capable of drawing even the most obvious conclusions". (Wylie 2003: 35, quoting Neely 1992: 185)

Here being objectified (treated like 'a piece of furniture') and regarded as lacking epistemic agency — as being incapable of undertaking even the simplest inquiry — offers opportunities for epistemic resistance of the sort discussed by Pohlhaus; it allows White to gather crucial information which she can then withhold until it suits her own purposes, strategically appearing ignorant to those around her in the meantime. Again, we only miss such possibilities if we conflate the perspective of 'the Graces of the world' with our own.

\section{Epistemic Objectification Enriched}

Having resisted Pohlhaus's arguments for an account of the primary harm of testimonial injustice in terms of epistemic othering rather than epistemic objectification, I want to close by considering what can be said in favour of the latter. I'll made two related points. First, I'll argue that Emmalon Davis's examples, introduced above, are more troubling for accounts built around the notion of derivatization than she acknowledges, and that the objectification account has a much simpler account available (one inspired by Davis herself). Finally, I'll look at the extent to which the Nussbaum-inspired version of the objectification account offers additional resources, apparently unmatched by the derivatization account, that can be put to work in diagnosing the harm in different cases of testimonial injustice.

First, let's revisit Davis's examples that proved troublesome for Fricker's account of the primary harm. These involved speakers receiving credibility excesses due to prejudices-for example, so-called positive stereotypes-and they are problematic for Fricker because they involve a subject being harmed by testimonial injustice without being 'regarded simply as passive states of affairs or inert objects from which information might be gleaned nor ...excluded from epistemic participation' (2016: 489). However, although Davis appeals to such examples to motivate a shift away from Fricker's account and towards Pohlhaus's, she recognises that her examples in fact raise a problem for Pohlhaus. In Davis's cases,

it is only because a marginalized speaker possesses what dominant others perceive to be socially and epistemically distinct experiences that she is acknowledged at all. The problem with [such cases of credibility excess] is not that one is not permitted to contribute in ways that are perceived to extend beyond dominant experiences; rather, the problem is that one is only permitted (and expected to) contribute in ways that are considered "unique" and "distinct." That is, it is not that one's epistemic capabilities are exclusively confined to what is seen as derivative of the dominant; rather, one's epistemic capabilities are exclusively confined to what the dominant perceives to be essentially nonderivable. (Davis 2016: 490) 
Davis doesn't think this spells the end for Pohlhaus's account, but rather shows that it needs to be 'revised slightly' (2016: 489). Here is Davis's revised proposal:

[W]e may characterize the primary, or intrinsic, harm of epistemic injustice as a form of epistemic othering, through which the capacities of a speaker are prejudicially assessed in such a way that bypasses or circumscribes the speaker's subjectivity. (2016: 490)

This preserves the core of Pohlhaus's proposal, as Davis sees it: namely, the idea that a speaker subject to a testimonial injustice is unable to simply testify in accordance with her lived experiences and be taken seriously. Her capacity to contribute something is always assessed with respect to the experiences of the dominant, so that she is liable to suffer a credibility deficit or excess if what she said conflicts with the dominant picture of the world or extends beyond it in the wrong way. However, this already seems like a complication of Pohlhaus's proposal, and it needs to be complicated still further. As I've stressed, cases like that of Tom Robinson don't involve speakers whose epistemic capacities are being doubted; rather it's their sincerity that's called into question. Davis's proposal doesn't accommodate this point as it stands, since it frames the harm of testimonial injustice in terms of prejudicial assessments of a speaker's epistemic capacities.

In any case, as I noted above, Davis also gestures at a simpler and better account of the harm done to the speaker in her cases of credibility excess; they involve speakers who are treated as epistemically fungible (2016: 488). That's a diagnosis of the example that can be readily absorbed by the modification of Fricker's account I've proposed, as I've shown above.

This illustrates a more general point about the advantages of the version of the objectification account that I favour. I've joined in the criticisms of Fricker's version on the grounds that it focuses too much on imputed epistemic inertness. Freed of that focus, an account of the primary harm in terms of epistemic objectification inherits all of the flexibility and richness of Nussbaum's cluster analysis of objectification. Subjecting someone to a testimonial injustice, on this account, involves treating them as object-like in some way, but there are very different ways in which one may do this. We've already seen examples which arguably involve epistemic analogues of instrumentality, inertness, and fungibility, and there are epistemic analogues of the other ways of objectifying on Nussbaum's list. If it should prove that this richness helps us to diagnose the harms in variant cases of testimonial injustice, that would be a point in favour of the kind of account of the primary harm I'm advocating - one that an account in terms of derivatization may have a hard time matching. Let's see how we might put Nussbaum's 'cluster' to work in epistemology, then. My aim here is to be suggestive rather than comprehensive, and so I won't try to discuss every item on Nussbaum's list. Rather, I'll pick out one which I think I think is promising and worthy of further consideration.

I'll focus on violatability, which Nussbaum characterises as treating something as 'permissible to break up, smash, break into' (1995: 257). As an example, here's Beauvoir's discussion of the 'destruction' of a woman's virginity in The Second Sex:

every desire pursues the aim of consuming the desired object, entailing its destruction. By breaking the hymen, man possesses the feminine object more intimately than by a penetration that leaves it intact; in this irreversible operation, he unequivocally makes it a passive object, asserting his hold on it. (1949/2011: 178-9)

What might an epistemic analogue of this look like? I think we get a clue from the film Inception, which involves an operation to plant a thought into someone's mind in such a way that they think 
that it was their own. The suggestion I want to take from this is that one way to treat someone as lacking boundary-integrity, in their role as an epistemic subject, is to act towards them as if it's permissible to interfere relatively directly with their beliefs about the world, without their consent. Talk of 'relatively direct' interference is vague, but it's meant to contrast with ways of trying to bring a person rationally on-board with something: argumentation, exposing them to relevant evidence, and so on. Are there realistic cases of testimonial injustice which are plausibly treated as involving this kind of epistemic objectification? Here's a speculative suggestion.

Consider gaslighting, which Kate Abramson characterises as emotionally manipulating someone in order to 'induce in someone the sense that her reactions, perceptions, memories and/or beliefs are not just mistaken, but utterly without grounds' (2014: 2). My aim here is not to try to offer a general account of the wrongs involved in gaslighting, so understood (as Kate Abramson does in her illuminating paper). Rather, I want to look at some cases of testimonial injustice that involve gaslighting, to see if these might show where we could put the notion of epistemic violatability to work.

Plausibly, some cases of testimonial injustice are also cases of gaslighting, though the exact relationship between these, and more generally the extent to which gaslighting should be theorized about in epistemological terms, is controversial (e.g. Abramson 2014, Fricker 2017, Ivy (publishing as McKinnon) 2017 and 2019, Stark 2019, and Spear forthcoming). I don't want to take a stand on the broader issues here; for my purposes, it's enough that we recognise some overlap between cases of testimonial injustice and gaslighting, and this seems to be conceded on all sides. In particular, Abramson argues that the wrongs of gaslighting go beyond those of testimonial injustice, but she concedes that gaslighting can be a form of testimonial injustice (2014: 18). In such cases, a speaker's testimony is dismissed by her audience in such a way, or in such circumstances, so as to constitute an attempt to induce in the speaker a sense that she in fact has no grounds for the knowledgeable belief she is trying to share. We might already detect gaslighting in Herbert Greenleaf's response to Marge Sherwood; he doesn't merely suggest she's wrong, but that she has no basis for her suspicions whatsoever, since (in his eyes) she's merely relying on 'female intuition' which has no power to get at the facts. Other examples involve a speaker's testimony about her own experiences being dismissed as 'crazy', 'paranoid', and 'over-sensitive', or being shut down by a withdraw of support or a threat (Abramson 2014). It's crucial to this point that the gaslighting here involves manipulation - emotional manipulation - rather than rational persuasion; one doesn't treat another person as lacking epistemic boundary integrity just by thinking it's permissible to try to persuade them by force of argument or evidence that they are wrong (though even this attitude would be harmful in some examples of gaslighting). Rather, one manipulates them into thinking that their beliefs are without any foundation and that they are being 'crazy' or 'oversensitive' to the point where they should cease to trust their own perceptions, memories, and inferences, where this has the aim of destroying the possibility of disagreement on the issue at hand (Abramson 2014: 10, Spear forthcoming).

As stressed, I intend this discussion of violatability and gaslighting to be circumscribed, tentative, and speculative. It's not intended as an account of what's going on in all cases of gaslighting, and it's not intended as a rival to Abramson's rich discussion of the wrongs involved in gaslighting in general. In particular, I don't mean to take issue with Abramson's contention that these wrongs can outstrip those that are inherent to testimonial injustice. She examines the kinds of 'leverage' that gaslighters rely on, such as their victim's love or empathy for them, or their dependence on the gaslighter's goodwill or support, and suggests that there's a distinctive wrong involved in the exploitation of this kind of leverage. Veronica Ivy adds a further source of leverage 
in an example she gives, namely the status of the certain people as 'allies' and as thereby shielded from suspicion and criticism (Ivy, publishing as McKinnon, 2017: 171). I don't take issue with any of these points. But I've proposed that we conceive of the moral/epistemic harm in cases of testimonial injustice that feature gaslighting as that of treating someone as violatable in their role as epistemic agents, where this involves certain forms of manipulation aimed at destroying that person's capacity to oppose the view one would prefer them to have. The account of the primary harm of testimonial injustice I favour lets us see this as a neglected form of epistemic objectification. Though much work remains to be done, I hope that this examples provides some grounds for optimism that, as the literature on testimonial injustice continues to expand its focus beyond its initial diet of examples, this version of the objectification account continues to offer resources which help us to articulate the harms involved.

\section{Final Remarks}

The proposal I've just made concerning what an epistemic analogue of lack of boundary integrity might look like raises a natural and reasonable objection, one that has implications for the whole project I'm engaged in. In effect, what I've just suggested is that there are ways of treating someone as an object which build in that one sees them as a creature with certain kinds of psychological states, and as vulnerable to certain kinds of emotional manipulation. Isn't this just to stretch the notion of objectification beyond all recognition? I don't think so, and in a way, this is a central point of the larger project that this paper is intended to contribute to. I want to try to show, both in social epistemology and more generally, that Nussbaum's account of objectification provides an illuminating and useful resource, once freed of any assumption that objectification invariably involves imputing a lack of agency, autonomy, or subjectivity. Moreover, I don't think this distorts how the concept of objectification has figured in feminist and other critiques of problematic behaviour, practices, and representations.

Finally, I want to stress that I don't want to rule out a role for othering in diagnosing the harms of testimonial injustice, or more generally in accounting for the harms of various kinds of injustice. I haven't discussed othering as a kind of mis- or non-recognition at all, and I've left open the possibility that the notion of othering as derivatization may yet have its place. Indeed, I think it's plausible that offering a full account of the harms of testimonial injusticeand not merely focusing on the primary harm, as I have here - will require us to appeal to both the notions of epistemic objectification and epistemic othering.

Acknowledgements This paper grew out of my presentation at the 2019 SWIP-UK Annual Conference: Epistemic Injustice, Reasons, and Agency, held at the University of Kent. I'd like to thank the organisers of that event, Veli Mitova and Lubomira Radoilska, and all of the participants for very helpful discussion. Particular thanks are due to two anonymous referees for this journal, who prompted many improvements, and to Jennifer Saul, whose questions in Kent got me thinking about what an epistemic analogue of Nussbaum's violability would look like.

Open Access This article is licensed under a Creative Commons Attribution 4.0 International License, which permits use, sharing, adaptation, distribution and reproduction in any medium or format, as long as you give appropriate credit to the original author(s) and the source, provide a link to the Creative Commons licence, and indicate if changes were made. The images or other third party material in this article are included in the article's Creative Commons licence, unless indicated otherwise in a credit line to the material. If material is not included in the article's Creative Commons licence and your intended use is not permitted by statutory regulation or exceeds the permitted use, you will need to obtain permission directly from the copyright holder. To view a copy of this licence, visit http://creativecommons.org/licenses/by/4.0/. 


\section{References}

Abramson K (2014) Turning up the lights on Gaslighting. Philos Perspect 28:1-30

Alcoff LM (2010) Epistemic Identities. Episteme 7(2):128-137

Anderson E (2012) Epistemic justice as a virtue of social institutions. Soc Epistemol 26(2):163-173

Cahill A (2011) Overcoming objectification: a carnal ethics. Routledge, New York and Oxon

Congdon M (2017) What's wrong with epistemic injustice? Harm, vice, objectification, misrecognition. In: Kidd IJ, Medina J, Pohlhaus G Jr (eds) The Routledge handbook of epistemic injustice. Routledge, Oxon, pp 243-253

Cusick C (2019) Testifying bodies: testimonial injustice as derivatization. Soc Epistemol 33(2):111-123

Davis E (2016) Typecasts, tokens, and spokepersons: a case for credibility excess as testimonial injustice. Hypatia 31:485-501

de Beauvoir S (1949/2011) The second sex. Translated by Constance Borde and Sheila Malovany-Chevallier. Vintage Books, London

Fricker M (2007) Epistemic injustice: power and the ethics of knowing. Oxford University Press, Oxford

Fricker M (2017) Evolving concepts of epistemic injustice. In: Kidd IJ, Medina J, Pohlhaus G Jr (eds) The Routledge handbook of epistemic injustice. Routledge, Oxon, pp 53-60

Fricker M (2018) Epistemic injustice and recognition theory: a new conversation — afterword. Fem Philos Q 4(4):1-5

Gerken M (2019) Pragmatic encroachment and the challenge from epistemic injustice. Philosophers' Imprint 19: 1-19

Giladi P (2017) Epistemic injustice: a role for recognition? Philos Soc Critic 44(2):141-158

Honneth A (1995) The struggle for recognition: the moral grammar of social conflicts. Polity Press, Cambridge and Oxford

Ivy V (2017) Allies behaving badly: gaslighting as epistemic injustice. In: Kidd IJ, Medina J, Pohlhaus G Jr (eds) The Routledge handbook of epistemic injustice. Routledge, Oxon, pp 167-175 (Published as Rachel McKinnon)

Ivy V (2019) Gaslighting as epistemic violence: "allies," mobbing, and complex posttraumatic stress disorder, including a case study of harassment of transgender women in sport. In: Sherman B, Goguen S (eds) Overcoming epistemic injustice: social and psychological perspectives. Rowman and Littlefield International, London and New York, pp 285-301 (Published as Rachel McKinnon)

Langton R (2005) Autonomy-denial in objectification. Reprinted in Rae Langton, Sexual Sexual Solipsism: Philosophical Essays on Pornography and Objectification. Oxford: Oxford University Press, pp 223-40

Langton R (2010) Epistemic injustice: power and the ethics of knowing by Miranda Fricker. Hypatia 25(2):459464

Lee H (1960) To kill a mockingbird. Arrow Books, London

Maitra I (2010) The nature of epistemic injustice. Philos Books 51(4):195-211

Manne K (2018) Down girl: the logic of misogyny. Oxford University Press, Oxford

McConkey J (2004) Knowledge and acknowledgement: 'epistemic injustice' as a problem of recognition. Politics 24(3):198-205

McGlynn A (Forthcoming) Epistemic objectification as the primary harm of testimonial injustice. Episteme:1-17

Medina J (2013) The epistemology of resistance: gender and racial oppression, epistemic injustice, and resistant imaginations. Oxford University Press, Oxford

Medina J (2018) Misrecognition and epistemic injustice. Fem Philos Q 4(4):1-16

Mikkola M (2016) The wrong of injustice: dehumanization and its role in feminist philosophy. Oxford University Press, Oxford

Minghella A (2000) The talented Mr Ripley_-based on Patricia Highsmith's novel. Methuen, London

Neely B (1992) Blanche on the lam. Penguin Books, New York

Nussbaum M (1995) Objectification. Philos Public Aff 24(4):249-291

Pohlhaus G Jr (2014) Discerning the primary epistemic harm in cases of testimonial injustice. Soc Epistemol 28(2):99-114

Spear A (Forthcoming) Epistemic dimensions of gaslighting: peer-disagreement, self-trust, and epistemic injustice. Inquiry

Stark C (2019) Gaslighting, misogyny, and psychological oppression. Monist 102:221-235

Wanderer J (2012) Addressing testimonial injustice: being ignored and being rejected. Philos Q 62:148-169

Wylie A (2003) Why standpoint matters. In: Figueroa R, Harding S (eds) Science and other cultures. Routledge, Oxon and New York, pp 26-48

Yap A (2017) Credibility excess in the social imaginary in cases of sexual assault. Fem Philos Q 3:1-24

Publisher's Note Springer Nature remains neutral with regard to jurisdictional claims in published maps and institutional affiliations. 